\title{
PELATIHAN PIJAT BAYI KEPADA KADER POSYANDU DESA MABUNG KECAMATAN BARON KABUPATEN NGANJUK
}

\author{
*Dewi Kartika Sari' ${ }^{1}$, Halimatus Saidah ${ }^{2}$, Sutrisni $^{3}$, Miftakhul Mu'alimah ${ }^{4}$, Putri \\ Wahyu Wigati ${ }^{5}$, Eko Winarti ${ }^{6}$, Sri Haryuni ${ }^{7}$, Rita Moris Suares ${ }^{8}$, Avita Arista ${ }^{9}$, Ni \\ Wayan $^{10}$, Nuranti ${ }^{11}$, Siti Hartina ${ }^{12}$ \\ 1, 2, 3, 4,5,6,7,8,9,10,11,12 Fakultas Ilmu Kesehatan, Universitas Kadiri \\ Email : dewikartika@unik-kediri.ac.id
}

\begin{abstract}
Baby massage is a relaxation technique that has been practiced for generations in Indonesia. The problem found in partners is the lack of knowledge of Posyandu activities about the importance of baby massage and how to massage babies properly and correctly, while the Posyandu activities is an important person for the community because as one of the community mobilizers in maternal and child health and family planning, therefore the cadre need to get training about baby massage. The objectives of this activity are to improve the quality of the baby's health and increase Posyandu activities knowledge about baby massage. The method that will be carried out in this activity is the identification of Posyandu activities' knowledge of infant massage then training Posyandu activities on the importance of baby massage and the implementation of baby massage properly and correctly with the number of participants is 23 participants. Based on the results of the training, there was an increase in Posyandu activities knowledge about baby massage and Posyandu activities became aware of how to massage babies properly. This is expected to be implemented in society so that the welfare of the baby increases.
\end{abstract}

Key word $\quad$ : Posyandu activities, baby, baby massage

\begin{abstract}
ABSTRAK
Pijat bayi adalah sebuah teknik relaksasi yang telah turun temurun dipraktekkan di Indonesia. Permasalahan yang ditemukan pada mitra adalah masih rendahnya pengetahuan kader tentang pentingnya pijat bayi serta cara memijat bayi dengan baik dan benar, sedangkan kader merupakan orang yang penting bagi masyarakat karena sebagai salah satu penggerak masyarakat dalam kesehatan ibu dan anak serta KB, maka dari dari itu kader perlu mendapatkan pelatihan tentang pijat bayi. Tujuan yang ingin dicapai dari kegiatan ini adalah meningkatkan kualitas kesehatan bayi dan meningkatkan pengetahuan kader tentang pijat bayi. Metode yang akan dilaksanakan pada kegiatan ini adalah identifikasi pengetahuan kader tentang pijat bayi kemudian melakukan pelatihan kepada kader tentang pentingnya pijat bayi. Berdasarkan hasil pelatihan, terdapat peningkatan pengetahuan kader tentang pijat bayi dan kader menjadi mengerti tentang cara memijat bayi dengan baik dan benar.
\end{abstract}

Kata Kunci : kader, bayi, pijat bayi 


\section{PENDAHULUAN}

Pijat bayi adalah sebuah teknik relaksasi yang telah turun temurun dipraktekkan di Indonesia. para ahli kesehatan bayi juga telah mengakui manfaat pijat bayi bagi kesehatan dan tumbuh kembang bayi. Namun, sebuah penelitian lebih lanjut menemukan bahwa pijat bayi tidak hanya memberikan manfaat besar bagi tumbuh kembang fisik si kecil, namun juga memberikan manfaat besar bagi perkembangan otak, mental dan panca indera (Bobak, 2004) selain itu Manfaat lain dari pemijatan pada bayi adalah meningkatnya keyakinan pemberi pijatan dalam mengurus bayi itu (Turner, 2010) sesuai dengan penelitian yang dilakukan uummi kalsum pada tahun tahun 2014 yang menyatakan bahwa pijat bayi juga berpengaruh positif pada perkembangan bayi (Kasum, 2014).

Angka kematian bayi di Indonesia paling tinggi di Asia Tenggara, yang mencapai 32/1.000 kelahiran hidup. Tingginya angka kematian anak lebih disebabkan oleh kurangnya stimulus dan nutrisi, bukan karena keberadaan ekonomi kurang ( Ronald, 2011). Maka dari itu Johnson \& Johnson telah secara aktif memperkenalkan program pijat bayi kepada profesional sejak tahun 1977. Johnson \& johnson telah bekerjasama dengan profesional kesehatan untuk mentransfer konsep dan pengetahuan tentang pijat bayi kepada masyarakat (Roesli, 2001). Sesungguhnya praktek pijat bayi tidak hanya terdapat di Indonesia, metode kesehatan ini juga dipraktekkan oleh orang-orang di berbagai belahan dunia. Bahkan para ahli medis modern telah pula melakukan penelitian mengenai manfaat pijatan bagi bayi. Diantaranya adalah mempererat ikatan emosional antara sang bayi dengan Ibunya. Bayi yang di pijat secara berkala mempunyai pertumbuhan yang lebih baik ketimbang bayi yang tidak dipijat. Bayi yang dipijat memiliki perkembangan sistem motorik yang lebih baik, pola tidur yang teratur, pengenalan terhadap lingkungannya serta memiliki ketenangan emosi yang lebih baik pula.

Desa Mabung merupakan desa yang terdapat di Kabupaten Nganjuk. Berdasarkan survey awal yang telah dilakukan, dari 8 kader didapatkan 6 kader mengenti tentang pijat pijat bayi, tetapi masih pijat bayi yang konvesional (dilakukan oleh dukun), maka dari itu perlu adanya pelatihan mengenai manfaat ataupun langkah-langkah pijat bayi dengan baik dan benar agar kader mengerti tentang pijat bayi sehingga bisa menggerakan masyarakat untuk melakukan pijat bayi yang baik dan benar sehingga angka morbiditas dan mortalitas pada bayi di desa Mabung menjadi berkurang.

\section{METODE PELAKSANAAN}


Kegiatan pelatihan pijat bayi bagi kader dilaksanakan di desa Mabung Kecamatan Baron Kabupaten Nganjuk Pada bulan Desember tahun 2019, kegiatan ini dilakukan dengan memberikan pelatihan pijat bayi kepada kader, sebelum dilaksanakan pelatihan dilakukan pre test dulu untuk menilai pengetahuan kader tentang pijat bayi dan setelah pelatihan dilakukan post test untuk menilai kemampuan kader setelah dilakukan pijat bayi.

\section{HASIL DAN PEMBAHASAN}

1. Pelaksanaan Kegiatan

Lembaga Penelitian dan Pengabdian kepada Masyarakat (LP3M) Fakultas Ilmu Kesehatan Universitas Kadiri dalam melaksanakan semua gerak dan langkah didukung oleh berbagai sumber daya dari berbagai jurusan sesuai dengan program penyuluhan yang ditawarkan. Pelatihan pijat bayi dalam kegiatan Pengabdian Masyarakat ini mencapai keberhasilan karena dukungan berbagai pihak yang terkait dan mau bekerjasama dengan baik, yaitu pihak mitra (sasaran) yaitu desa Mabung Kecamatan Baron Kabupaten Nganjuk. Keberhasilan kerjasama juga terjadi karena akar permasalahan diperoleh dari pihak mitra sendiri. Pelaksanaan kegiatan dilakukan di Bulan Desember tahun 2019. Kegiatan dilaksanakan dalam bentuk pelatihan kepada Kader desa Mabung Kec. Baron Kab. Nganjuk.

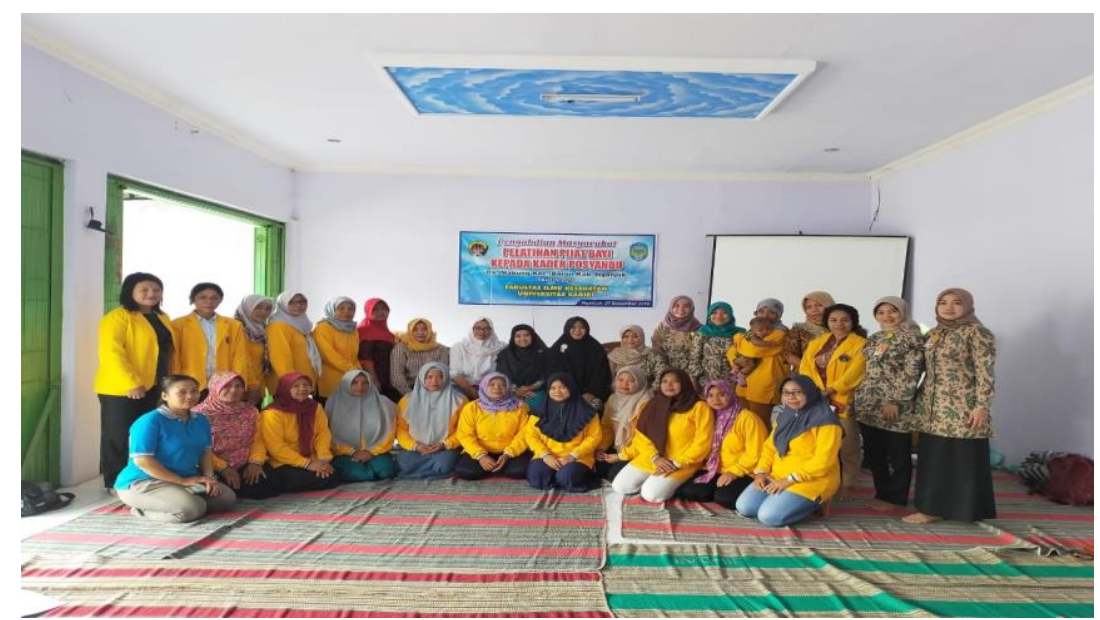

Gambar 1. Foto Bersama Pemateri dan Kader Desa Mabung Kec. Baron Kab. Nganjuk 


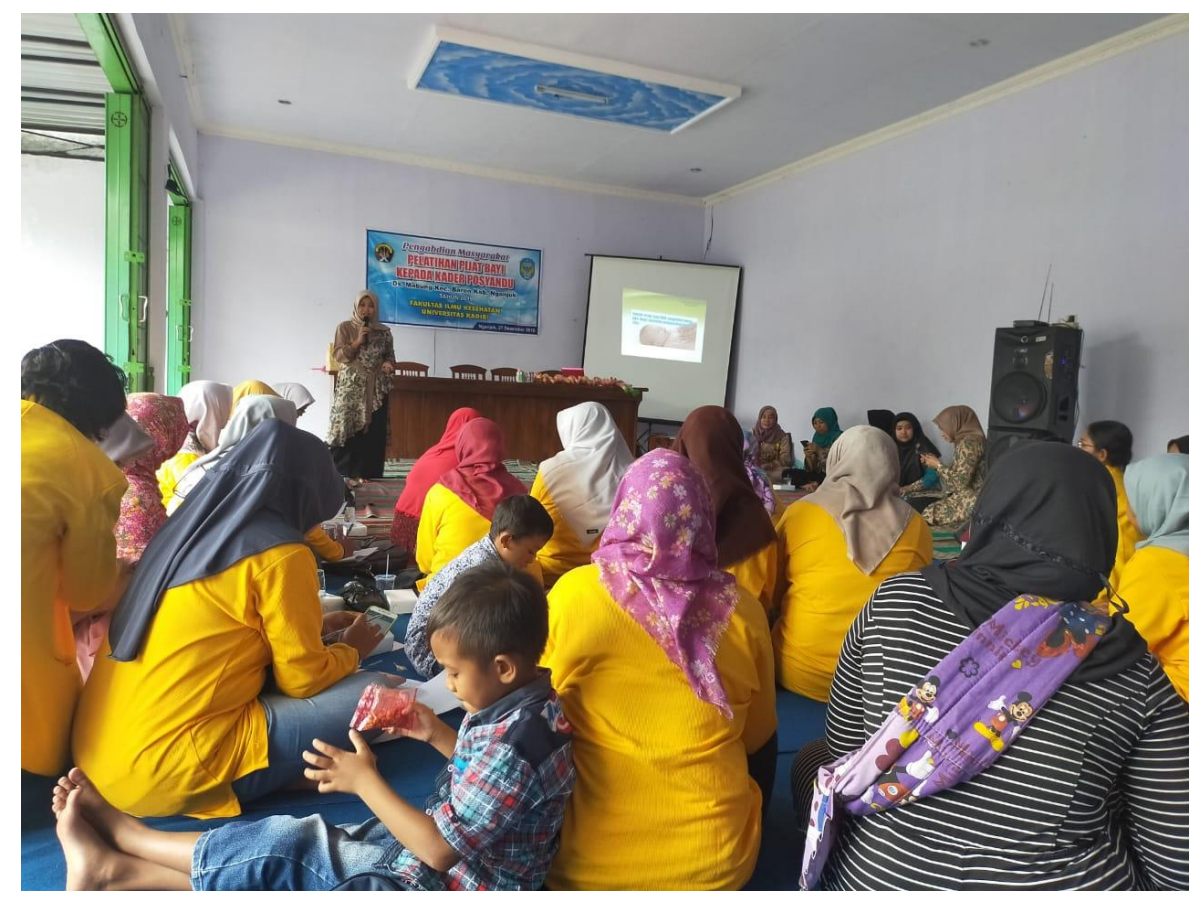

Gambar 2. Kegiatan Pemberian Materi

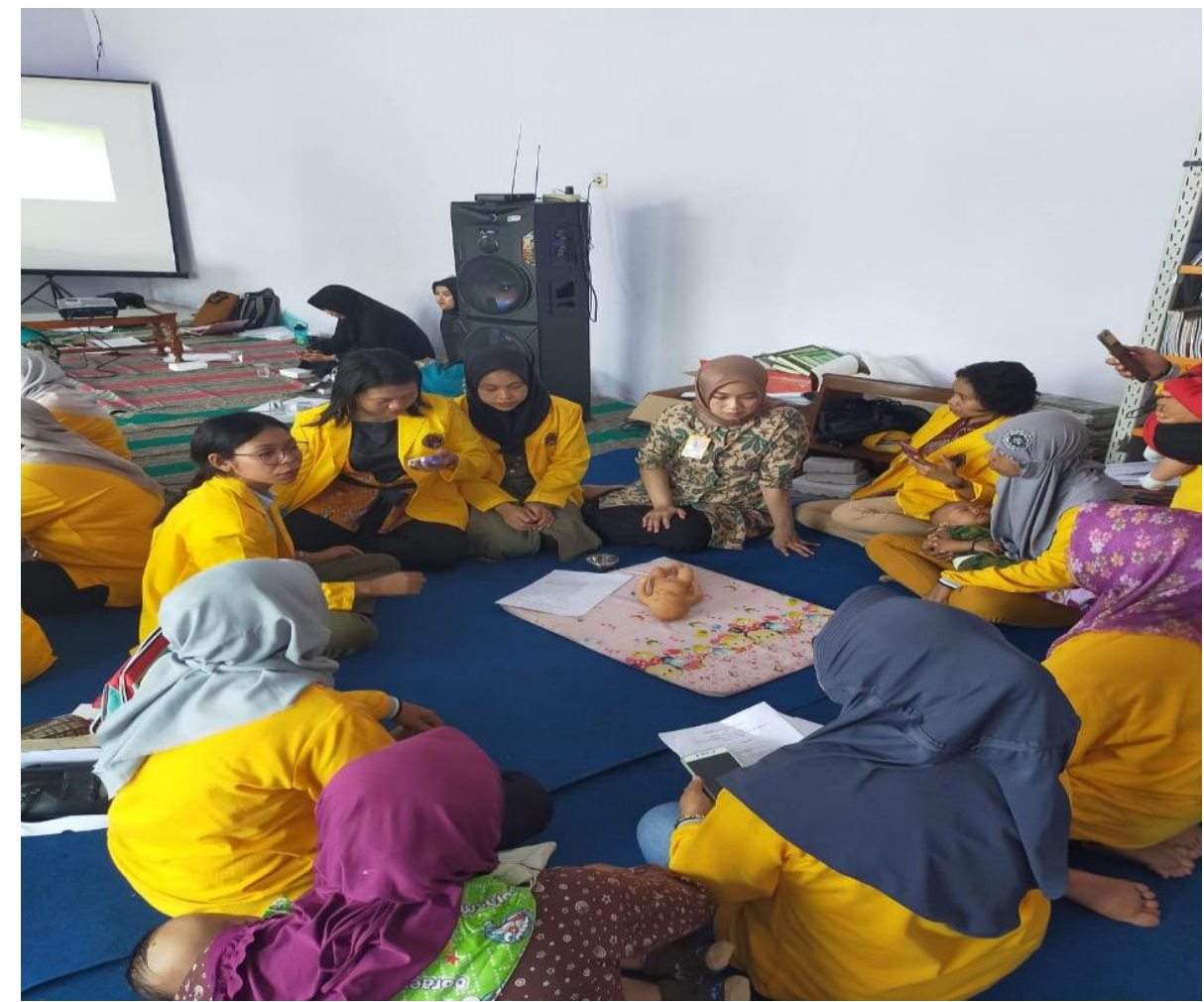

Gambar 3. Kegiatan Praktek Pijat Bayi

(C) 2020 Jurnal Abdi Masyarakat Universitas Kadiri | 40 


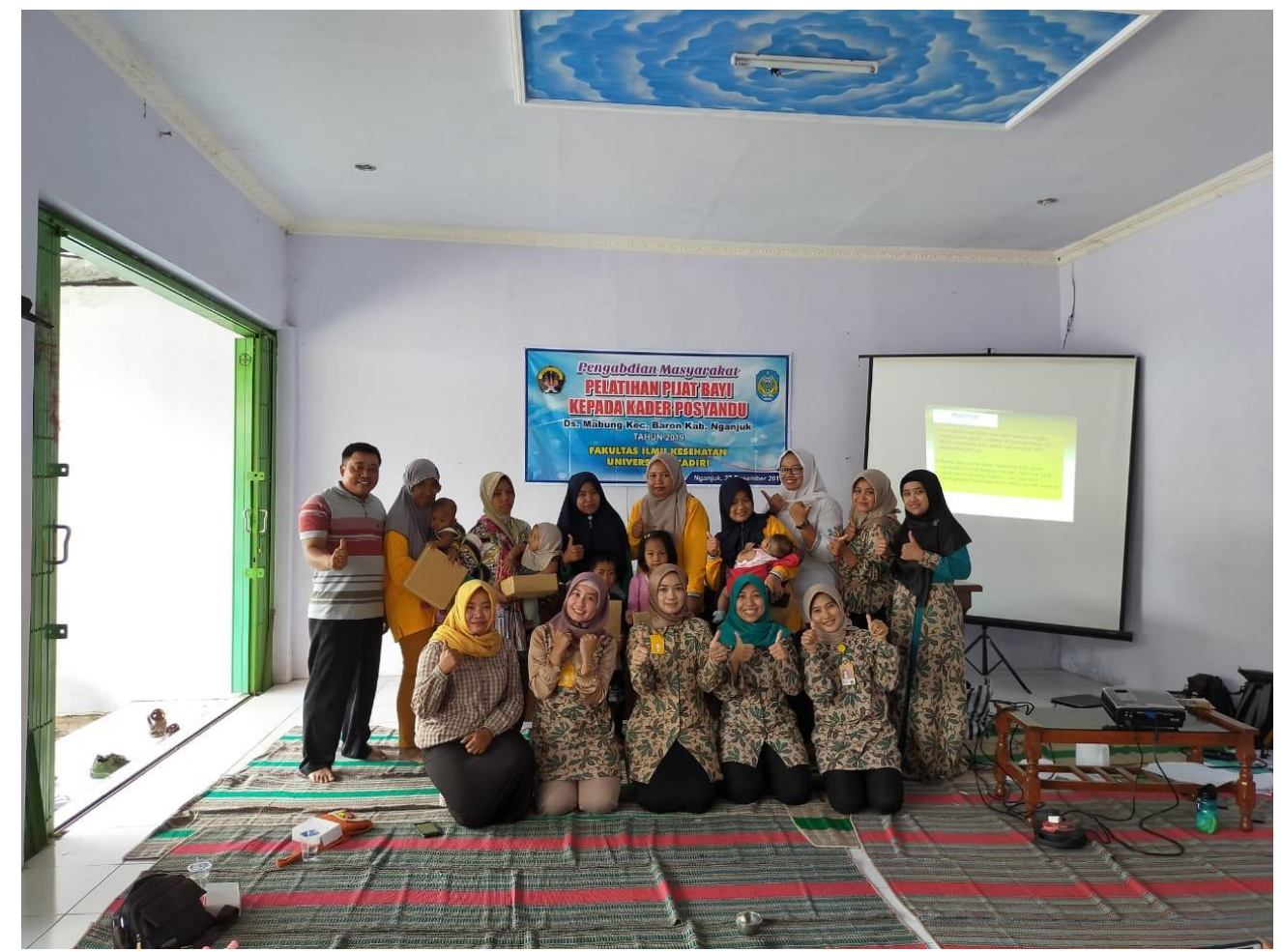

Gambar 4. Pemberian Doorprize kepada Kader yang berprestasi

\section{Penyelesaian Permasalahan}

\subsection{Identifikasi Pengetahuan Masyarakat}

Tabel 1 Klasifikasi Pengetahuan tentang Pijat Bayi

\begin{tabular}{|c|l|c|c|}
\hline No. & \multicolumn{1}{|c|}{ Klasifikasi } & Frekuensi & Prosentase (\%) \\
\hline 1 & Baik & 7 & 30,4 \\
\hline 2 & Cukup & 12 & 52,2 \\
\hline 3 & Kurang & 4 & 17,4 \\
\hline \multicolumn{2}{|c|}{ Jumlah } & 23 & $100 \%$ \\
\hline
\end{tabular}

Berdasarkan tabel 1 didapatkan hasil bahwa sebanyak 12 Kader $(52,2 \%)$ masih memiliki pengetahuan yang Cukup tentang Pijat Bayi.

\subsection{Pelatihan tentang Pijat Bayi}

Sebelum dilakukan pekatihan, pelatihan menggunakan LCD proyektor dan pantum bayi mengenai pelaksanaan Pijat Bayi. Tujuan diberikan penyuluhan ini adalah agar kader posyandu mengetahui tentang pijat bayi. 
Pelatihan dilaksanakan di desa Mabung Kec. Baron Kab. Nganjuk selama 70 menit. Sebelum diberikan penyuluhan dilakukan pres tes terlebih dahulu untuk mengetahui pengetahuan tentang Pijat Bayi. Setelah dilakukan pelatihan juga dilaksanakan post tes untuk mengetahui keefektifan pelatihan yang telah diberikan. Hasil dari post test tersebut tersaji dalam tabel 2

Tabel 2 Hasil post tes penyuluhan tentang Pijat Bayi

\begin{tabular}{|c|l|c|c|}
\hline No. & \multicolumn{1}{|c|}{ Klasifikasi } & Frekuensi & Prosentase \\
\hline 1 & Baik & 21 & 91,3 \\
\hline 2 & Cukup & 2 & 8,4 \\
\hline 3 & Kurang & - & - \\
\hline \multicolumn{2}{r|}{ Jumlah } & 23 & 100 \\
\hline
\end{tabular}

Berdasarkan tabel 2 didapatkan hasil bahwa 21 Kader (91,3\%) memiliki pengetahuan yang baik tentang Pijat.

\section{DAFTAR PUSTAKA}

Kasum, Umi. 2014. Peningkatan Berat Badan Bayi Melalui Pemijatan. Jurnal Keperawatan Indonesia, Volume 17 No.1, Maret 2014, hal 25-29 pISSN 1410-4490, eISSN 23549203

Roesli, U. 2001. Pedoman Pijat Bayi. Jakarta : Trubus Agriwidya

Roesli, U. 2009. Pendoman Pijat Bayi Prematur \& Bayi Usia 0-3 Bulan. Trubus Agriwidya: Jakarta

Ronald. 2011. Pedoman dan Perawatan Balita Agar Tumbuh Sehat dan Cerdas. Bandung: CV Nuansa Aulia.

Soetjiningsih. 2001. Tumbuh Kembang Anak. Jakarta : EGC

Turner, R 2010, Pedoman Praktis Pemijatan Bayi, Kharisma, Tangerang. 